\title{
Research Paper: Examination of the Psychometric Properties of the Persian Version of the Multidimensional Orientation Toward Dying and Death Inventory Among Students
}

Zahra Allame $^{1}$ (D), Leila Heydarinasab ${ }^{2 *}$ (D), Motahare Fasanghari ${ }^{3}$ (D), Maryam Shahmohammadi ${ }^{1}$

1. Department of Clinical Psychology, University of Social Welfare and Rehabilitation Sciences, Tehran, Iran. 2. Department of Clinical Psychology, Faculty of Litretures and Humanities, Shahed University, Tehran, Iran. 3. Department of Clinical Psychology, Faculty of Educational Sciences and Psychology, University of Alzahra, Tehran, Iran.

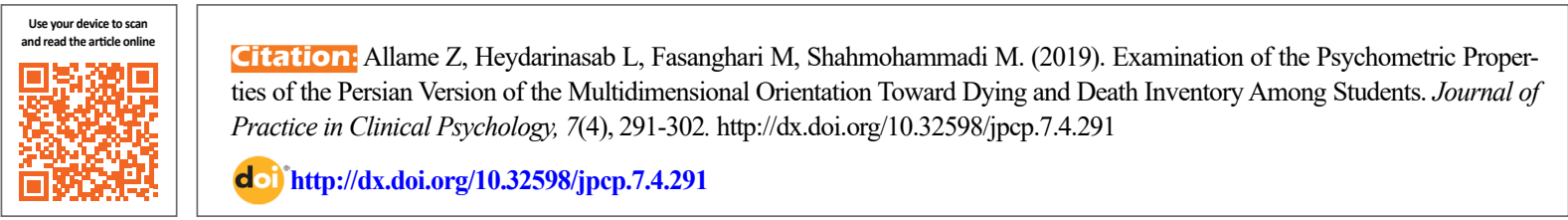

\section{(c) (1) (\$)}

Article info:

Received: 02 Apr 2019

Accepted: 07 Jul 2019

Available Online: 01 Oct 2019

\section{Keywords:}

Death, Dying, Death attitude, Psychometric, Validity, Reliability, Factor analysis

\section{ABSTRACT}

Objective: Attitude toward dying and death is a conceptual response to the various aspects of death, which is based on an individual's psychosocial and cultural experiences. The present study aimed to examine the psychometric properties of the Persian version of the Multidimensional Orientation toward Dying and Death Inventory (MODDI-F) among Iranian students.

Methods: A total of 320 subjects were selected from students in universities of Tehran in the academic year 2016-2017, using the convenience sampling method. The study data were collected using the following instruments: the MODDI-F, the Existential Anxiety Scale (EAS), the Oxford happiness questionnaire, the general health questionnaire, and the Death Anxiety Scale (DAS). Data analyses were performed by factor analysis, Pearson correlation, and Cronbach's alpha coefficient in SPSS V. 22.

Results: Factor structure was assessed using the confirmatory factor analysis. The proposed model for the MODDI-F with 8 factors had a good fit to the data. Besides, the reliability of the MODDI-F was assessed using Cronbach alpha and test-retest reliability coefficients. The Cronbach alpha values of higher than 0.7 were found for all of the subscales, except for death denial. Moreover, using the Pearson correlation coefficient, significant relationships were found between the scores on the factors of the MODDI-F and scores on convergent and divergent factors of other questionnaires, indicating the convergent and divergent validity of the inventory.

Conclusion: MODDI-F enjoys acceptable psychometric properties regarding the ease of administration, scoring, and interpretation, as well as the suitable validity and reliability of the questionnaire. Thus, researchers can safely use it in their studies. 


\section{Highlights}

- The Persian version of the MODDI-F has acceptable validity and reliability.

- A Cronbach's alpha of higher than 0.70 were found for all of the subscales of MODDI-F, expect for the subscale of death denial.

- A significant relationship was found between the scores of the MODDI-F components and the scores of convergent and divergent factors in the EAS, OHQ, GHQ, and DAS questionnaires.

\section{Plain Language Summary}

Many previous instruments about death were not based on true theory and well-explained conceptual assumptions. Besides, most of the existing instruments are only focused on anxiety related to death and dying. Few instruments are available to assess death acceptance, and none is appropriate for assessing the constructs of acceptance and fear of death in a multidimensional way. The Multidimensional Orientation Toward Dying and Death Inventory (MODDI-F) is the only instrument assessing death acceptance and death denial, along with death anxiety. The MODDI-F is based on the main assumption that people' reactions toward dying can be divided into three dimensions of fear, acceptance, and denial. These dimensions are the most important ways of thinking and feeling about death. MODDI-F consists of 8 subscales of fear of one's own dying, fear of one's own death, fear of another person's dying, fear of another person's death, fear of corpses, acceptance of one's own dying and death, acceptance of another person's death, and denial of one's own death. The present study aimed to examine the psychometric properties of the Persian version of the MODDI-F. Results showed the acceptable validity and reliability of its Persian version. A Cronbach's alpha of higher than 0.70 were found for all of the subscales of MODDI-F, expect for the subscale of death denial. A significant relationship was found between the scores of the MODDI-F components and the scores of convergent and divergent factors in the EAS, OHQ, GHQ, and DAS questionnaires.

\section{Introduction}

n contrast to other creatures, human beings are aware of their mortality and adopt different attitudes in dealing with this knowledge (Wittkowski, Ho, \& Chan, 2011). The multicomponent from social psychology attitude is regarded as summarizing the evaluation of an object based on the cognitive, affective, and behavioral information (Groebe et al., 2018). Attitudes toward death are influenced by various factors, including age, gender, health status, beliefs system, internal religious orientation, perceived dangers, adverse life events, death-related knowledge and experiences, sociocultural beliefs, moral values, and spiritual beliefs (Kawano, 2011; Nia et al., 2014; Soleimani, Yaghoobzadeh, Bahrami, Sharif, \& Sharif Nia, 2016; Zana, Szabó, \& Hegedűs, 2009).

Attitude toward death and dying is an essential aspect of thanatology that can be called the process of understating the interdependence between life and death (Yalom, 1980). This concept, as a psychological topic, was first introduced in the late 1950s thanks to the studies by Feifel who were focused on aging and mental disorders (Feifel, 1956; Feifel, H. 1959). Attitude toward death and dying is not necessarily a negative thing like fear of death, but neutral and even positive attitudes can be understood under the concept of acceptance (Gesser, Wong, \& Reker, 1988).

Studies on people on their deathbed have introduced a 5 -stage model of reactions toward death and dying. In this model, the first reaction is denial, during which one tries to silence or neutralize the awareness of their own death (Kübler-Ross, 1973). Much research on death attitudes has had to do with matters to death anxiety (Corr, Corr, \& Doka, 2018). But, anxiety about death can be demonstrated in different forms, such as worries, depression, or paradoxes. Also, this construct can be manifested while facing the illness or death of a loved one (Wong \& Tomer, 2011). The second reaction occurs when one becomes hopeless and shows anger toward the undeniable and unjust nature of death. The third reaction involves bargaining and trying to buy time for living. The fourth reaction is depression that leads to isolation, silence, and 
grief. The final response is the acceptance of the inevitability of death that leads to emotional stability and trying to get prepared for death (Westman, 1992). Death acceptance refers to the informed acknowledgment of the inevitability of death (the cognitive component) that leads to positive emotions (emotional component) (Neimeyer, Moser, \& Wittkowski, 2003).

According to the studies on death acceptance, this construct is divided into 3 categories: approach acceptance, avoidant acceptance, and neutral acceptances. Approach acceptance is a positive form of death acceptance that is achieved through self-actualization and overcoming the fear of death by trying to find meaning in life. Neutral death acceptance considers death an inevitable part of life. Those with this attitude toward death have cognitively accepted the reality of death as an unavoidable aspect of life, and gradually adapt themselves to its emotional aspects; but, they are still worried about what could happen to them when death arrives. People with avoidant acceptance focus on life problems instead of fear of death and describe life as unbearable. They believe that hell is more tolerable than the pains of life; therefore, they may choose suicide as a way of getting rid of life (Neimeyer, 2015).

Early studies on death were focused on projective methods (such as the examination of death-related themes based on the thematic apperception test), but these methods lacked good reliability (Neimeyer, Wittkowski, \& Moser, 2004). Collette and Lester (Collett \& Lester, 1969), Krieger, Epting, and Leitner (Krieger, Epting, \& Leitner, 1975), and Templer (Templer, 1970) were the first researchers, who specifically focused on different aspects of death and developed scales assessing death, death threat, and death anxiety, respectively.

Many previous instruments about death were not based on true theory and well-explained conceptual assumptions. Besides, most of the existing instruments are only focused on anxiety related to death and dying. Few instruments are available to assess death acceptance, and none is appropriate for assessing the constructs of acceptance and fear of death in a multidimensional way. The Multidimensional Orientation toward Dying and Death Inventory (MODDI-F) is the only instrument assessing death acceptance and death denial, along with death anxiety. The MODDI-F is based on the main assumption that people' reactions toward dying can be divided into three dimensions of fear, acceptance, and denial. These dimensions are the most important ways of thinking and feeling about death (Wittkowski, 2001). MODDI-F consists of 8 subscales of fear of one's own dying, fear of one's own death, fear of another person's dying, fear of another person's death, fear of corpses, acceptance of one's own dying and death, acceptance of another person's death, and denial of one's own death (MacDougall \& Farreras, 2016).

Attitude toward death is a transdiagnostic construct that increases one's susceptibility toward the development and maintenance of psychological disorders (Wittkowski, Ho, \& Chan, 2012). Given that in the cognitivebehavioral approach understanding the transdiagnostic constructs is an essential step in modifying maladaptive symptoms, therapists and researchers prioritize access to a valid and reliable instrument to assess this transdiagnostic construct (Iverach, Menzies, \& Menzies, 2014).

The essential role of culture in attitudes toward death and dying (Neimeyer et al., 2003) requires validating instruments like MODDI-F in the Iranian population. Therefore, the examination of cross-cultural differences using quantitative instruments can further our understanding of intrapersonal and interpersonal differences in attitudes toward death and dying and, finally, enrich our awareness of the true nature of this concept (Wittkowski et al., 2012).

The construct validity of MODDI-F has led to 47 items loaded on 7 factors. Four factors assess fear and 3 factors acceptance. This inventory is based on Collette and Lester's dimensional $2 \times 4$-factor model, including fear of death and acceptance. In the factor analysis, 8 factors were extracted for the inventory (MacDougall \& Farreras, 2016; Wittkowski, 2001; Wittkowski et al., 2011).

The positive correlations of fear and acceptance, as well as the negative relationship between the fear and acceptance dimensions, provided the theoretical data for the formation of scale and confirmed its construct validity (Wittkowski et al., 2012).

The previous review on measurement tools for death issues did not use a systematic and comprehensive approach. The present study aimed to examine the psychometric properties of the Persian version of MODDI-F because it is a comprehensive scale about dying and death that includes both acceptance and fear of death.

\section{Methods}

A descriptive correlational research design was used to conduct this study. The statistical population included students of the universities in Tehran in the academic year 2016-2017. The questionnaires were distributed among students in universities, and all the potential questions were responded by the researcher. The participants were 
selected using the convenience sampling method. The statistical analyses were performed in LISREL 8.80 and SPSS 23. After the items were translated and approved by an expert, the other expert back-translated items to English. Then, the two texts were compared and because of no significant differences between them, the inventory was prepared for administration.

For the assessment of the convergent and divergent validity of the questionnaire, MODDI-F was simultaneously correlated with the Oxford Happiness Questionnaire (OHQ), the Existential Anxiety Scale (EAS), the Death Anxiety Scale (DAS), and the General Health Questionnaire (GHQ). The confirmatory factor analysis was also used for assessing the construct validity of the inventory.

\section{Instruments}

Multidimensional Orientation toward Dying and Death Inventory (MODDI-F)

Multidimensional Orientation toward Dying and Death Inventory (MODDI-F) was originally developed by Wittkowski in Germany in 1996 and was validated and translated into English in 2001 (Wittkowski, 2001). It has 47 items that are rated on a 4-point Likert-type scale, ranging from 0 (completely disagree) to 3 (completely agree). The items are divided into 8 subscales, 4 of which assess fear, 3 assess acceptance, and 1 assesses death denial. Among the 47 items, items 9 and 38 are reverse scored (Wittkowski, 2001). In factors 1 to 5, higher scores indicate higher fear, but in factors 6 and 7, higher scores indicate higher acceptance toward death and dying. Higher scores on factor 8 also indicate higher death denial (MacDougall \& Farreras, 2016). MODDI-F has been translated into Chinese, English, and Brazilian Portuguese. It was also validated in a German sample in 2001, in Hong Kongese and Brazilian populations in 2012, and an American sample in 2016. The reliability values of MODDI-F range from $0.82-0.92$ for the German version, from 0.68-0.91 for the Chinese version, and from 0.820.92 for the American version (Feifel, H, 1956; MacDougall \& Farreras, 2016; Wittkowski, 1996). In addition, test-retest reliability for the factors of MODDI-F range from 0.79-0.89 (MacDougall \& Farreras, 2016).

\section{Existential Anxiety Scale (EAS)}

The Existential Anxiety Scale (EAS) was developed by Good and Good. It has 32 items assessing existential anxiety. The items are answered in the true/false format. Total scores range from 32-64, and higher scores indicate higher existential anxiety (Good \& Good, 1974).
In an Iranian sample, the reliability values of EAS were found 0.86 and 0.80 , using the internal consistency (Cronbach's alpha coefficient) and test-retest methods, respectively. Besides, a significant positive relationship was found between scores of EAS and scores of other similar scales indicated its convergent validity (Hooman, Rezaie, Rezaie, A, Shahriyar Ahmadi, and Baratian, 2011). Internal reliability in the present study was 0.88 .

\section{The Oxford happiness questionnaire}

The Oxford Happiness Questionnaire (OHQ) is a selfreport questionnaire and developed by Argyle. It contains 29 items rated on a 4-point Likert-type scale (Argyle, Martin, \& Crossland, 1989). The theoretical basis of this questionnaire is the definition of happiness by Argyle, and it measures happiness (Mahmoudi, Mahmoudi, Shamsaei, Raeisi Shahraki, and Kakaei, 2019). The total score of the questionnaire categorizes happiness level into 4 categories: unhappy or mildly depressed, a low level of happiness, a high level of happiness, and mania. The respondents are asked to select a statement from each group of statements that best describes their feelings in the past week. The reliability of this scale was found 0.91 in a study (Kamthan et al., 2019). Total scores range from 0-87 (Franice, Lester, \& Philipchalk, 2002). The validity and reliability of OHQ were assessed among the Iranian population. The Cronbach's alpha of 0.92 and test-retest reliability of 0.73 was reported for the questionnaire (Liaghatdar, Jafari, Abedi, \& Samiee, 2008). Internal reliability in the current study was 0.92 .

\section{General Health Questionnaire (GHQ)}

The general health questionnaire (GHQ) is a 28 -item questionnaire and a screening tool commonly used in epidemiological studies on mental disorders. It was first developed by Goldberg to identify mental disorders in different settings, including health facilities (Noorbala, Mohammad, \& Bagheri Yazdi, 2002). It measures general health and well-being (Hjelle et al., 2019). Goldberg and Hiller provided a revised version of the questionnaire. The items of GHQ are on 4 factors: physical symptoms, anxiety and sleep problems, impairment in social functioning, and severe depression (Goldberg \& Hillier, 1979). In a study on the psychometric properties of GHQ in the Iranian population, factor analysis led to the 4 factors mentioned above. The items are rated on a 4-point Likert-type scale, and the highest score is 84 (Noorbala et al., 2002). The Cronbach alpha values above 0.6 have been reported in an Iranian sample, indicating acceptable reliability and factor analysis using the principal component method identified 4 factors in 
participants' responses, and these 4 factors accounted for $60 \%$ of the total variance (Nojomi, Anbary, \& Ranjbar, 2008). Internal reliability in this study was 0.89 .

\section{Death Anxiety Scale (DAS)}

Templer developed the death anxiety scale (DAS) and it has 15 items (Lester, Templer, \& Abdel-Khalek, 2007). The true/ false format is the original response option. However, a few researchers have used DAS with a modified answer format, most often a 5-point Likert-type format with the anchors 1 (strongly disagree) to 5 (strongly agree) (Abdel-Khalek \& Neimeyer, 2017). Templer reported a Cronbach alpha of 0.76 and a test-retest reliability of 0.83 for the scale (Templer, 1970). In another study, the Cronbach alpha of 0.6 and test-retest reliability of 0.63 were found for the DAS among the Iranian population (Dadfar \& Lester, 2018). Internal reliability in the present study was 0.71 .

\section{Results}

Table 1. Factor loadings for the Multidimensional Orientation toward Dying and Death Inventory (MODDI-F) among students

\begin{tabular}{|c|c|c|c|c|c|c|c|c|}
\hline \multicolumn{9}{|c|}{ MODDI-F } \\
\hline Items & FODy-F & FODe-F & FOPDy-F & FOPDe-F & FC-F & AODD-F & AOPDe-F & RODe-F \\
\hline 1 & 0.52 & & & & & & & \\
\hline 8 & 0.75 & & & & & & & \\
\hline 16 & 0.51 & & & & & & & \\
\hline 23 & 0.37 & & & & & & & \\
\hline 31 & 0.63 & & & & & & & \\
\hline 37 & 0.67 & & & & & & & \\
\hline 43 & 0.50 & & & & & & & \\
\hline 46 & 0.47 & & & & & & & \\
\hline 5 & & 0.60 & & & & & & \\
\hline 13 & & 0.63 & & & & & & \\
\hline 20 & & 0.47 & & & & & & \\
\hline 28 & & 0.68 & & & & & & \\
\hline 35 & & 0.09 & & & & & & \\
\hline 42 & & 0.54 & & & & & & \\
\hline 3 & & & 0.23 & & & & & \\
\hline 10 & & & 0.72 & & & & & \\
\hline 18 & & & 0.55 & & & & & \\
\hline 25 & & & 0.76 & & & & & \\
\hline 33 & & & 0.75 & & & & & \\
\hline 39 & & & 0.46 & & & & & \\
\hline
\end{tabular}

Of the target population, 320 students were selected as the study sample including: 203 (63.4\%) men, 117 (36.6\%) women, with the mean age of 23.5 years and ranged from 18-47 years; 294 (91.8\%) single and $26(0.08 \%)$ married; and $150(46.8 \%)$ with BA degre, 147 (45.9\%) with MA degre, and $23(0.09 \%) \mathrm{PhD}$ students. The confirmatory factor analysis was used to examine the construct validity of the and Table 2 presents the goodness of fit indices.

As presented in Table 1, factors loadings for most items of the factors of death attitude are more than 0.40 . However, items 3, 14, 23, 29, 35, and 36 have factor loadings less than 0.30 . In the next step, the goodness of fit of the model was assessed, using the following indices: Chi-squared test $\left(\chi^{2}\right)$, Comparative Fit Index (CFI), Named Fit Index (NFI), Standardized Root Mean Square Residual (SRMR), Root Mean Square Error of Approximation (RMSEA), And Goodness Of Fit Index (GFI). The more the values of the CFI, NFI, Non-Normed Fit Index (NNFI), and GFI closer, the better the goodness of fit of the model. The $\chi^{2}$ is often used to assess goodness of fit, but it increases as sample size and degrees of freedom increase. Therefore, the two indices of SRMR and RMSEA should be used for this purpose (Hu and Bentler, 1999). According to Engel et al., SRMR values ranging from MODDI-F. Table 1 presents the factor loading of each item, 


\begin{tabular}{|c|c|c|c|c|c|c|c|c|}
\hline \multicolumn{9}{|c|}{ MODDI-F } \\
\hline Items & FODy-F & FODe-F & FOPDy-F & FOPDe-F & FC-F & AODD-F & AOPDe-F & RODe-F \\
\hline 7 & & & & 0.78 & & & & \\
\hline 15 & & & & 0.88 & & & & \\
\hline 22 & & & & 0.86 & & & & \\
\hline 30 & & & & 0.70 & & & & \\
\hline 12 & & & & & 0.72 & & & \\
\hline 27 & & & & & 0.76 & & & \\
\hline 41 & & & & & 0.70 & & & \\
\hline 45 & & & & & 0.81 & & & \\
\hline 4 & & & & & & 0.70 & & \\
\hline 11 & & & & & & 0.67 & & \\
\hline 19 & & & & & & 0.60 & & \\
\hline 26 & & & & & & 0.76 & & \\
\hline 34 & & & & & & 0.69 & & \\
\hline 40 & & & & & & 0.76 & & \\
\hline 44 & & & & & & 0.72 & & \\
\hline 47 & & & & & & 0.59 & & \\
\hline 2 & & & & & & & 0.61 & \\
\hline 19 & & & & & & & 0.48 & \\
\hline 17 & & & & & & & 0.75 & \\
\hline 24 & & & & & & & 0.75 & \\
\hline 32 & & & & & & & 0.64 & \\
\hline 38 & & & & & & & 0.57 & \\
\hline 6 & & & & & & & & 0.60 \\
\hline 14 & & & & & & & & 0.30 \\
\hline 21 & & & & & & & & 0.53 \\
\hline 29 & & & & & & & & 0.15 \\
\hline 36 & & & & & & & & 0.35 \\
\hline
\end{tabular}

0-0.05 indicate a good fit, and values ranging from 0.05-0.1 indicate an acceptable fit (Schermelleh-Engel, Moosbrugger, \& Müller, 2003). Besides, RMSEA values ranging from 0-0.05 indicate a good fit, and values ranging from 0.05-0.08 indicate an acceptable fit (Kline, 2015). Therefore, the model has a good fit to the data among the students (Table 2).

To examine the validity of the MODDI-F, the correlations between the subscale scores were calculated. There are significant positive correlations among the fear of death and death acceptance dimensions (Table 3). Also, there is a significant negative relationship between the fear of death and the death acceptance dimensions.

In the next step, to examine convergent and divergent validity, the correlation coefficients between the scores of death attitude dimensions and the scores of DAS, EAS, OHQ, and GHQ were calculated. The internal consistency (Cronbach's alpha coefficient) and the test-retest methods were used to examine reliability.

Test-retest reliability: In the present study, the sample included 43 students ( 22 women and 20 men) with a mean

Table 2. The goodness of fit indices for death attitude among students

\begin{tabular}{|c|c|c|c|c|c|c|c|c|c|}
\hline Items & Chi-square & $\mathbf{P}$ & df & RMSEA & SRMR & GFI & CFI & NFI & NNFI \\
\hline & 1817.01 & 0.001 & 1006 & 0.05 & 0.06 & 0.80 & 0.96 & 0.92 & 0.96 \\
\hline
\end{tabular}


Table 3. Matrix of correlations between the scores of the death attitude dimensions inclding, MODDI-F, DAS, EAS, OHQ, and GHQ

\begin{tabular}{|c|c|c|c|c|c|c|c|c|}
\hline $\begin{array}{l}\tilde{c} \\
\overline{\tilde{N}} \\
\frac{\hat{O}}{0}\end{array}$ & 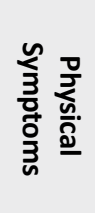 & 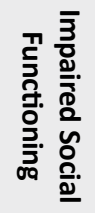 & $\begin{array}{l}\frac{0}{0} \\
\frac{0}{0} \\
\frac{0}{0} \\
\frac{\omega}{0} \\
\frac{0}{3}\end{array}$ & 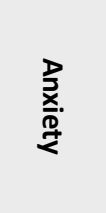 & 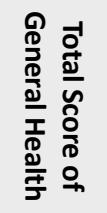 & 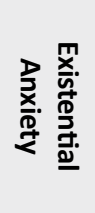 & 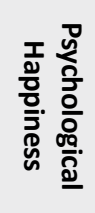 & 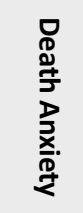 \\
\hline Fear of one's own dying & 0.13 & -0.06 & 0.17 & 0.09 & 0.15 & 0.03 & -0.11 & $0.5^{*}$ \\
\hline Fear of one's own death & 0.06 & -0.09 & 0 & 0.09 & 0.02 & -0.02 & -0.53 & $0.58^{*}$ \\
\hline Fear of another person's dying & 0.09 & -0.06 & 0.85 & 0.1 & 0.08 & -.01 & -0.04 & $0.41^{*}$ \\
\hline Fear of another person's death & 0.13 & -0.04 & 0.05 & $0.24^{*}$ & 0.13 & 0.05 & -0.09 & $0.33^{*}$ \\
\hline Fear of corpses & 0.05 & -0.01 & 0.10 & 0.13 & 0.09 & -0.01 & 0 & $0.4^{*}$ \\
\hline $\begin{array}{l}\text { Acceptance of one's own dying } \\
\text { and death }\end{array}$ & -0.10 & 0.04 & 0.02 & -0.1 & -0.04 & -0.02 & $0.27^{*}$ & $-0.41^{*}$ \\
\hline $\begin{array}{l}\text { Acceptance of another per- } \\
\text { son's death }\end{array}$ & -0.12 & 0.1 & -0.06 & $0.2^{* *}$ & -0.1 & -0.09 & $0.2^{* *}$ & $-0.35^{*}$ \\
\hline Denial of one's own death & 0.14 & 0.04 & 0.15 & $0.19 * *$ & $0.18^{* *}$ & $0.38^{*}$ & -0.03 & $0.42^{*}$ \\
\hline
\end{tabular}

${ }^{*} \mathrm{P}=0.05$

PRACTICE II IN PSYCH LOGY

**P $=0.01$

age of 22.83 years, who were selected, using the convenience sampling method. MODDI-F was completed by the participants on 2 occasions, 3 weeks to 1 month apart. Table 4 presents the Pearson correlation coefficients between the scores of the two administrations. in Tabel 5 there are details about internal consistensy coefficients for the subscales of the MODDI-F.
The test-retest reliability coefficients found for the MODDI-F and its subscales are within the acceptable range. All the correlation coefficients observed are significant at $\mathrm{P}<0.001$. More specifically, the correlations between the two administrations range from 0.7 (for acceptance of one's own dying and death) to 1 (for acceptance of another person's death and denial of one's own death)

Table 4. The Pearson correlation coefficients between the scores of the two administrations of the multidimensional orientation toward dying and death inventory $(n=42)$

\begin{tabular}{|c|c|c|c|c|}
\hline \multirow{3}{*}{$\begin{array}{l}\text { Index } \\
\text { Scale }\end{array}$} & \multirow{2}{*}{\multicolumn{2}{|c|}{$\begin{array}{c}\text { Administration } \\
\text { Mean } \pm S D\end{array}$}} & \multicolumn{2}{|c|}{$\begin{array}{l}\text { Correlation Coeffi- } \\
\text { cient }\end{array}$} \\
\hline & & & \multirow{2}{*}{$\mathbf{R}$} & \multirow{2}{*}{$\mathbf{P}$} \\
\hline & Frist & Second & & \\
\hline Fear of one's own dying & $10.19 \pm 5.91$ & $11.19 \pm 5.61$ & $0.77^{*}$ & 0 \\
\hline Fear of one's own death & $5.16 \pm 3.81$ & $5.16 \pm 3.50$ & $0.76^{*}$ & 0 \\
\hline Fear of another person's dying & $6.50 \pm 3.83$ & $6.50 \pm 4.14$ & $0.74 *$ & 0 \\
\hline Fear of another person's death & $6.07 \pm 3.40$ & $6.54 \pm 3.41$ & $0.77^{*}$ & 0 \\
\hline Fear of corpses & $3.73 \pm 3.57$ & $4.19 \pm 3.82$ & $0.79 *$ & 0 \\
\hline $\begin{array}{c}\text { Acceptance of one's own dying and } \\
\text { death }\end{array}$ & $14.71 \pm 6.06$ & $15.54 \pm 5.09$ & $0.7^{*}$ & 0 \\
\hline Acceptance of another person's death & $6.85 \pm 2.2$ & $6.85 \pm 2.2$ & $1^{*}$ & 0 \\
\hline Denial of one's own death & $2.96 \pm 2.48$ & $2.69 \pm 2.48$ & $1^{*}$ & 0 \\
\hline
\end{tabular}


Table 5. Internal consistency coefficients for the subscales of the MODDI-F

\begin{tabular}{cc}
\hline Subscale & Correlation Coefficient \\
\hline Fear of one's own dying & 0.75 \\
\hline Fear of one's own death & 0.70 \\
\hline Fear of another person's dying & 0.75 \\
\hline Fear of another person's death & 0.84 \\
Fear of corpses & 0.87 \\
\hline Acceptance of one's own dying and death & 0.87 \\
\hline Acceptance of another person's death & 0.79 \\
Denial of one's own death & 0.55 \\
\hline
\end{tabular}

Table 6. The results of $t$ test for the mean difference between male and female

\begin{tabular}{|c|c|c|c|c|c|}
\hline Index Scale & Gender & Mean士SD & Mean Difference & $\mathbf{t}$ & $\mathbf{P}$ \\
\hline Fear of one's own dying & $\begin{array}{c}\text { Male } \\
\text { Female }\end{array}$ & $\begin{array}{c}9.26 \pm 4.83 \\
10.53 \pm 5.23\end{array}$ & -1.27 & -2.2 & 0.02 \\
\hline Fear of one's own death & $\begin{array}{c}\text { Male } \\
\text { Female }\end{array}$ & $\begin{array}{l}5.23 \pm 3.54 \\
5.28 \pm 3.65\end{array}$ & -0.58 & -1.4 & 0.16 \\
\hline Fear of another person's dying & $\begin{array}{c}\text { Male } \\
\text { Female }\end{array}$ & $\begin{array}{l}5.75 \pm 3.93 \\
6.62 \pm 3.83\end{array}$ & -0.87 & -1.92 & 0.05 \\
\hline Fear of another person's death & $\begin{array}{c}\text { Male } \\
\text { Female }\end{array}$ & $\begin{array}{l}5.47 \pm 3.40 \\
7.07 \pm 3.33\end{array}$ & -1.23 & -3.38 & 0 \\
\hline Fear of corpses & $\begin{array}{c}\text { Male } \\
\text { Female }\end{array}$ & $\begin{array}{l}2.90 \pm 2.96 \\
4.00 \pm 3.49\end{array}$ & -1.09 & -2.97 & 0 \\
\hline Acceptance of one's own dying and death & $\begin{array}{c}\text { Male } \\
\text { Female }\end{array}$ & $\begin{array}{l}14.37 \pm 5.72 \\
13.47 \pm 6.07\end{array}$ & 0.9 & 1.32 & 0.18 \\
\hline Acceptance of another person's death & $\begin{array}{c}\text { Male } \\
\text { Female }\end{array}$ & $\begin{array}{l}9.64 \pm 4.33 \\
8.21 \pm 3.93\end{array}$ & 1.42 & 2.92 & 0 \\
\hline Denial of one's own death & $\begin{array}{c}\text { Male } \\
\text { Female }\end{array}$ & $\begin{array}{l}3.14 \pm 2.60 \\
2.68 \pm 2.24\end{array}$ & 0.45 & 1.59 & 0.11 \\
\hline Attitude toward death & $\begin{array}{l}\text { Male } \\
\text { Female }\end{array}$ & $\begin{array}{l}56.07 \pm 14.02 \\
58.43 \pm 16.38\end{array}$ & -2.36 & -1.36 & 0.17 \\
\hline
\end{tabular}


The Cronbach's alpha coefficient was calculated to examine internal consistency. The alpha coefficients for MODDI$\mathrm{F}$ and each of its subscales, except for denial of one's own death, are higher than the recommended value (0.7) (Bernstein \& Nunnally, 1994) and can be regarded as acceptable.

We used the independent samples $t$ test and compared the scores of male and female students to examine the effect of gender on the scores of the death attitude subscales. The results are presented in Table 6.

Women had significantly higher scores on fear of another person's death and fear of corpses compared with men. Also, men had significantly higher scores on acceptance of another person's death compared with women.

Analysis of the data showed that the inventory had good validity and reliability. Therefore, MODDI-F can be used to examine attitudes toward death and dying.

\section{Discussion}

The present study aimed at examining the psychometric properties of MODDI-F among Iranian students. The result of the confirmatory factor analysis was consistent with previous studies that confirmed the 8-factor structure of the inventory. Among the 8 confirmed factors, 5 were related to fear of death, 2 to death acceptance, and 1 to death denial (MacDougall \& Farreras, 2016; Wittkowski, 2001; Wittkowski et al., 2011). Examination of the goodness of fit indices indicated that the model had a good fit to the data. This finding is in line with those of previous studies examining the factor structures of the Chinese, Hong Kongese, and German versions of the inventory (Wittkowski, 1996; Wittkowski et al., 2012).

DAS was used to examine the convergent validity of the subscales related to fear of death and the divergent validity of the subscales related to death acceptance. Significant positive relationships were found between DAS and the two acceptance subscales. Also, significant negative relationships were found between DAS and the other subscales of MODDI-F. Moreover, a significant relationship was found between the existential anxiety construct assessed by EAS and death denial. This finding agrees with the opinions of existential psychologists and the results of previous studies (Westman, 1992; Yalom, 1980). For example, it was entirely similar to Westman 's finding because both of them found a relationship between existential anxiety and death denial, not any other aspect of death and dying (Westman, 1992). In addition, the results indicated a significant positive relationship between happiness assessed by $\mathrm{OHI}$ and death acceptance, which is similar to a previous study (AbdelKhalek, 2005). Abdel-Khalek in his research, found the negative correlation between happiness and death depression among women. Moreover, significant positive correlations were observed between the anxiety subscale of GHQ and 3 subscales of MODDI-F, including fear of one's own death, fear of another person's death, and denial of one's own death; this finding is in line with previous studies, showing a positive relationship between the death anxiety construct and the anxiety subscale of GHQ (Mohammadi, Ghorbani, \& Abdollahi, 2010).

The test-retest examination with a 3-week interval $(\mathrm{N}=42)$ showed that the MODDI-F had good reliability, and the correlations of two administrations of the inventory ranged from 0.7-1. This finding is consistent with previous studies, reporting good test-retest reliability estimates for MODDI-F. The Cronbach alpha coefficient was calculated to examine internal consistency. Alpha values ranging from $0.70-0.87$ were found for most of the subscales that indicate adequate reliability (Bernstein \& Nunnally, 1994). On the whole, the present data show high coefficients of internal consistency, the favorable shape of frequency distributions of the subtests, and evidence of the construct, as well as the differential validity of the Chinese version of MODDI-F. Thus, the instrument is comparable to the original German version. However, the reliability of denial of one's own death subtest is not satisfactory compared with its German predecessor. The alpha value for the death denial subscale was below 0.55 that is not in the acceptable range. This finding is not consistent with previous studies(Wittkowski, 1996). This inconsistency indicates the need for more studies to assess the reliability of this subscale.

The results of $t$ test indicated no significant difference between the female and male participants on attitude toward death and fear of one's own death, acceptance of one's own dying and death, and denial of one's own death subscales. However, there were significant differences in fear of one's own dying, fear of another person's dying, fear of another person's death, fear of corpses, and acceptance of another person's death subscales. This result is consistent with previous studies, showing that women obtain significantly higher scores on fear of one's own death and fear of corpses (MacDougall \& Farreras, 2016).

Because of the limited number of studies on this topic, it is essential to comprehensively examine attitudes toward death and dying. An instrument with excellent psychometric properties will have significant clinical implications and helps researchers assess this construct in differ- 
ent samples and conduct comparative studies in different groups. The results of this study confirmed the psychometric properties of MODDI-F among Iranian students that can pave the way for more studies on this topic.

The present study had some limitations, too. First, the study population consisted of students, and the convenience sampling method was used to recruit the participants that limited the generalizability of the results. Therefore, future studies are suggested to use the MODDI-F among participants from different age groups, socioeconomic backgrounds, and clinical samples, including those receiving end-of-life care in hospital settings.

\section{Ethical Considerations}

\section{Compliance with ethical guidelines}

The participants took part with their consent, and all of them willingly responded to the questionnaires. The confidentiality of information was assured. To this end, the participants were required to write their age, gender, marital status, grade, and not their names.

\section{Funding}

This study was approved and funded by Deputy of Research of Shahed University, Iran.

\section{Authors' contributions}

syudy concept and design: Leila Heydarinasab and Zahra allame; analysis af data: Motahare Fasanghari; data collecting: Maryam Shahmohammadi; drafting: Zahra allame; statistical analysis: Leila Heydarinasab and Zahra allame.

\section{Conflict of interest}

The authors declared no conflict of interest.

\section{Acknowledgments}

we wish to very thankful of Research Deputy Staff of Shahed University. moreover, authors are grateful students that contributed in data collecting.

\section{References}

Abdel-Khalek, A. M. (2005). Happiness and death distress: Two separate factors. Death Studies, 29(10), 949-58. [DOI:10.1080/07481180500299394] [PMID]
Abdel-Khalek, A. M., \& Neimeyer, R. A. (2017). Death Anxiety Scale. In Abdel-Khalek, A. M., \& Neimeyer, R. A. (Eds.), Encyclopedia of Personality and Individual Differences, New York: Spiringer. [DOI:10.1007/978-3-319-28099-8_21-1]

Argyle, M., Martin, M., \& Crossland, J. (1989). Happiness as a Function of Personality and Social Encounters. In J. P. Forgas, \& J. M. Innes (Eds.), Recent Advances in Social Psychology: An International Perspective (pp. 189-247). North-Holland: Elsevier Science Publishers.

Bernstein, I. H., \& Nunnally, J. C. (1994). Psychometric theory. New York: McGraw-Hill.

Collett, L. J., Lester, D. (1969). The fear of death and the fear of dying. The Journal of Psychology, 72(2), 179-81. [DOI:10.1080/0 0223980.1969.10543496] [PMID]

Corr, C. A., Corr, D. M., \& Doka, K. J. (2018). Death $\mathcal{E}$ dying, life $\mathcal{E}$ living: Cengage learning. Boston: Cengage.

Dadfar, M., \& Lester, D. (2018). The Farsi translation, reliability and validity of the Death Concern Scale. Trends in Psychiatry and Psychotherapy, 40(2), 114-25. [DOI:10.1590/2237-60892017-0078] [PMID]

Feifel, H. (1956). Older persons look at death. Geriatrics, 11, 127-30.

Feifel, H. E. (1959). The meaning of death. New York: McGrawHill.

Franice, L., Lester, D., \& Philipchalk, R. (2002). Happiness stable extraversion: A cross examination of the reliability and validity oxford happiness inventory among students in Theuk, ESA, Australia and Canada. Personality and Individual Differences, 24, 164-71. [DOI:10.1016/S0191-8869(97)00170-0]

Gesser, G., Wong, P. T., \& Reker, G. T. (1988). Death attitudes across the life-span: The development and validation of the Death Attitude Profile (DAP). OMEGA-Journal of Death and Dying, 18(2), 113-28. [DOI:10.2190/0DQB-7Q1E-2BER-H6YC]

Goldberg, D. P., \& Hillier, V. F. (1979). A scaled version of the General Health Questionnaire. Psychological Medicine, 9(1), 139-45. [DOI:10.1017/S0033291700021644] [PMID]

Good, L. R., \& Good, K. C. (1974). A preliminary measure of existential anxiety. Psychological Reports, 34(1), 72-4. [DOI:10.2466/ pr0.1974.34.1.72] [PMID]

Groebe, B., Strupp, J., Eisenmann, Y., Schmidt, H., Schlomann, A., Rietz, C., et al. (2018). Measuring attitudes towards the dying process: A systematic review of tools. Palliative Medicine, 32(4), 815-37. [DOI:10.1177/0269216317748889] [PMID]

Hjelle, E. G., Bragstad, L. K., Zucknick, M., Kirkevold, M., Thommessen, B., \& Sveen, U. (2019). The General Health Questionnaire-28 (GHQ-28) as an outcome measurement in a randomized controlled trial in a Norwegian stroke population. BMC Psychology, 7(1), 1-11. [DOI:10.1186/s40359-0190293-0] [PMID] [PMCID]

Hooman, H., Rezaie N., Rezaie, A., Shahriyar Ahmadi, M., \& Baratian, M. (2011). [Examination of the validity and reliability of the Existential Anxiety Questionnaire (EAQ) among high-school students in Ilam (Persian)]. Educational Measurement, 8(13), 143-66. [DOI:10.22111/jeps.2011.713]

Hu, L. t., \& Bentler, P. M. (1999). Cutoff criteria for fit indexes in covariance structure analysis: Conventional criteria versus 
new alternatives. Structural Equation Modeling: A Multidisciplinary Journal, 6(1), 1-55. [DOI:10.1080/10705519909540118]

Iverach, L., Menzies, R. G., \& Menzies, R. E. (2014). Death anxiety and its role in psychopathology: Reviewing the status of a transdiagnostic construct. Clinical Psychology Review, 34(7), 580-93. [DOI:10.1016/j.cpr.2014.09.002] [PMID]

Kamthan, S., Sharma, S., Bansal, R., Pant, B., Saxena, P., Chansoria, S., et al. (2019). Happiness among second year MBBS students and its correlates using Oxford Happiness Questionnaire. Journal of Oral Biology and Craniofacial Research, 9(2), 1902. [DOI:10.1016/j.jobcr.2018.06.003] [PMID] [PMCID]

Kawano, S. (2011). A sociocultural analysis of death anxiety among older Japanese urbanites in a citizens' movement. OMEGA-Journal of Death and Dying, 62(4), 369-86. [DOI:10.2190/OM.62.4.d]

Kline, R. B. (2015). Principles and practice of structural equation modeling. New York: Guilford Publications.

Krieger, S. R., Epting, F. R., \& Leitner, L. M. (1975). Personal constructs, threat and attitudes toward death. OMEGA-Journal of Death and Dying, 5(4), 299-310. [DOI:10.2190/WCDW-PNPQOERV-RNM7]

Kübler-Ross, E. (1973). On death and dying. London: Routledge. [DOI:10.4324/9780203010495]

Lester, D., Templer, D. I., \& Abdel-Khalek, A. (2007). A crosscultural comparison of death anxiety: A brief note. OMEGAJournal of Death and Dying, 54(3), 255-60. [DOI:10.2190/W6448645-6685-358V]

Liaghatdar, M. J., Jafari, E., Abedi, M. R., \& Samiee, F. (2008) Reliability and validity of the Oxford Happiness Inventory among university students in Iran. The Spanish Journal of Psychology, 11(1), 310-3. [DOI:10.1017/S1138741600004340] [PMID]

MacDougall, E. E., \& Farreras, I. G. (2016). The Multidimensional Orientation Toward Dying and Death Inventory (MODDIF): factorial validity and reliability in a US sample. Journal of Pain and Symptom Management, 51(6), 1062-9. [DOI:10.1016/j. jpainsymman.2015.12.322] [PMID]

Mahmoudi, A., Mahmoudi, F., Shamsaei, M., Raeisi Shahraki, H., \& Kakaei, H. (2019). Determination of the Level of Happiness among Students of Shiraz University of Medical Sciences, Iran. Journal of Research in Medical and Dental Science, $7(2), 52-6$.

Mohammadi, M., Ghorbani, N., \& Abdollahi, A. (2010). The Mortality Salience and Self-Esteem: An experimental study. Developmental Pscychology, 7(25), 57-64.

Neimeyer, R. A. (2015). Death anxiety handbook: Research, instrumentation, and application. London: Taylor \& Francis. [DOI:10.4324/9781315800813] [PMCID]

Neimeyer, R. A., Moser, R. P., \& Wittkowski, J. (2003). Assessing attitudes toward dying and death: Psychometric considerations. OMEGA-Journal of Death and Dying, 47(1), 45-76. [DOI:10.2190/EP4R-TULM-W52G-L3EX]

Neimeyer, R. A., Wittkowski, J., \& Moser, R. P. (2004). Psychological research on death attitudes: An overview and evaluation Death Studies, 28(4), 309-40. [DOI:10.1080/07481180490432324] [PMID]
Nia, H. S., Ebadi, A., Lehto, R. H., Mousavi, B., Peyrovi, H., \& Chan, Y. H. (2014). Reliability and validity of the persian version of templer death anxiety scale-extended in veterans of Iran-Iraq warfare. Iranian Journal of Psychiatry and Behavioral Sciences, 8(4), 29-37.

Nojomi, M., Anbary, K., \& Ranjbar, M. (2008). Health-related quality of life in patients with HIV/AIDS. Archives of Iranian Medicine, 11(6), 608-12.

Noorbala, A., Mohammad, K., \& Bagheri Yazdi, S. (2002). Mental health status in population 15 years and older in Tehran (Iran). Hakim Medical Journal, 5(1), 1-10.

Schermelleh-Engel, K., Moosbrugger, H., \& Müller, H. (2003). Evaluating the fit of structural equation models: Tests of significance and descriptive goodness-of-fit measures. Methods of Psychological Research Online, 8(2), 23-74.

Soleimani, M. A., Yaghoobzadeh, A., Bahrami, N., Sharif, S. P., \& Sharif Nia, H. (2016). Psychometric evaluation of the Persian version of the Templer's Death Anxiety Scale in cancer patients. Death Studies, 40(9), 547-57. [DOI:10.1080/07481187 .2016.1187688] [PMID]

Templer, D. I. (1970). The construction and validation of a death anxiety scale. The Journal of General Psychology, 82(2), 165-77. [DOI:10.1080/00221309.1970.9920634] [PMID]

Westman, A. S. (1992). Existential anxiety as related to conceptualization of self and of death, denial of death, and religiosity. Psychological Reports, 71(suppl. 3), 1064-6. [DOI:10.2466/ pro.1992.71.3f.1064]

Wittkowski, J. (1996). [Fragebogeninventar zur mehrdimensionalen Erfassung des Erlebens gegenüber Sterben und Tod:(FIMEST) (Germani)]. Toronto: Hogrefe.

Wittkowski, J. (2001). The construction of the multidimensional orientation toward dying and death inventory (MODDI-F). Death Studies, 25(6), 479-95. [DOI:10.1080/07481180126858] [PMID]

Wittkowski, J., Ho, S. M., \& Chan, W. C.-H. (2012). The Chinese version of the multidimensional orientation toward dying and death inventory (MODDI-F/chin): an introduction. OMEGA-Journal of Death and Dying, 64(1), 15-27. [DOI:10.2190/ OM.64.1.b]

Wittkowski, J., Ho, S. M., \& Chan, W. C. (2011). Factor structure of the multidimensional orientation toward dying and death inventory among Hong Kong college students: A preliminary study. Death Studies, 35(1), 59-72. [DOI:10.1080/07481187.201 0.502612] [PMID]

Wong, P. T., \& Tomer, A. (2011). Beyond terror and denial: The Positive Psychology of Death Acceptance. London: Taylor \& Francis. [DOI:10.1080/07481187.2011.535377] [PMID]

Yalom, I. D. (1980). Existential Psychotherapy (Vol. 1). New York: Basic Books.

Zana, Á., Szabó, G., \& Hegedús, K. (2009). Attitudes toward death in Hungary using the Multidimensional Fear of Death Scale. Clinical and Experimental Medical Journal, 3(2), 327-35. [DOI:10.1556/CEMED.3.2009.2.12] 
This Page Intentionally Left Blank 